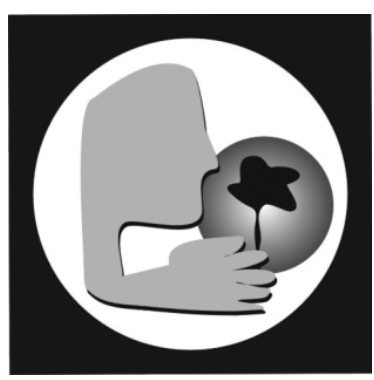

Sustentabilidade e $m$ Debate
Recebido em 18.02.2011

Aceito em 13.03.2011

\section{Conflitos Socioambientais, Educação Ambiental e Participação Social na Gestão Ambiental}

\author{
Carlos Hiroo Saito ${ }^{1}$, Aloísio Ruscheinsky ${ }^{2}$, Fabio da \\ Purificação de Bastos ${ }^{3}$, Jacy Bandeira Almeida Nunes ${ }^{4}$, \\ Luciano Fernandes Silva ${ }^{5}$, Luiz Marcelo de Carvalho ${ }^{6}$
}

${ }^{1}$ Doutor em Geografia, Professor da Universidade de Brasília, Departamento de Ecologia e Programa de Pós-Graduação em Desenvolvimento Sustentável, Brasília-DF, Brasil. carlos.saito@pq.cnpq.br, carlos.h.saito@hotmail.com

${ }^{2}$ Doutor em Sociologia, Professor da Unisinos, Centro de Ciências Humanas, São Leopoldo-RS, Brasil. aloisior@unisinos.br

${ }^{3}$ Doutor em Educação. Professor da Universidade Federal de Santa Maria, Centro de Educação, Santa Maria-RS, Brasil. fbastos@ce.ufsm.br

${ }^{4}$ Mestre em Educação e Contemporaneidade, Professora da Universidade do Estado da Bahia, Campus IV Jacobina, Departamento de Ciências Humanas, Jacobina-BA, Brasil. jacy_bandeira@yahoo.com.br

${ }^{5}$ Doutor em Educação, Professor da Universidade Federal de Itajubá, Departamento de Física e Química, Itajubá-MG, Brasil. lufesilva@uol.com.br

${ }^{6}$ Doutor em Educação, Professor da Universidade Estadual Paulista Júlio de Mesquita Filho, Departamento de Educação, Rio Claro-SP, Brasil.luiz.marcelo@pq.cnpq.br

Palavras-chave: educação ambiental; conflitos socioambientais; participação social; razão instrumental; interesse emancipatório; Paulo Freire

Key-words:environmental education;

socioenvironmental conflicts; social participation; instrumental rationality; emancipatory interest; Paulo Freire

\section{RESUMO}

Trata-se da síntese da mesa-redonda "Conflitos Socioambientais, Educação Ambiental e Participação Social na Gestão Ambiental" realizada no V ENANPPAS (2010), que teve como foco principal a discussão de quatro temas: Conflitos socioambientais e os mitos da participação social; Conflitos socioambientais e as incertezas das condições para a educação ambiental em meio aos problemas e conflitos; Resolução de Conflitos socioambientais - ações mediadas pela razão instrumental e interesse emancipatório; Ações positivas como práticas dialógicoproblematizadoras. A partir de um texto inicial provocativo, cada debatedor trouxe sua contribuição em forma de texto, seguida de novas questões oriundas dessas intervenções. O conjunto do debate foi gravado, transcrito e sintetizado para apresentação neste artigo.

\section{ABSTRACT}

This is synthesis of the debates held during the round-table "Socioenvironmental conflicts, environmental education and social participation on environmental management", at the V ENANPPAS (2010), which has focused on the discussion of four main themes: Socioenvironmental conflicts and the myths of social participation; Socioenvironmental conflicts and the uncertainty of conditions to environmental education immersed in problems and conflicts; Solution of Socioenvironmental conflitcts - actions mediated by instrumental rationality and emancipatory interest; Positive actions as dialogical-problematizing practice on concrete reality. From an initial provocative text, each member has brought his first contribution, followed by new questions as consequence of these speeches. The hole debate was recorded, transcripted and made a synthesis to present in this manuscript form. 


\section{Introdução}

Os conflitos socioambientais são tidos como situações-problema presentes no cotidiano vivido, cuja complexidade é fundamental ser diagnosticada.

A discussão que requer aprofundamento diz respeito à possibilidade de se obter um ganho significativo na efetivação de políticas públicas na área ambiental na medida em que conflitos socioambientais forem compreendidos como fontes de um processo de ensino-aprendizagem. Para tal, considera-se fundamental a problematização da realidade a partir de situações-problema, o mapeamento e a explicitação dos conceitos-chave e secundários envolvidos, e aqueles necessários e operacionalizados nas soluções dessas mesmas situações-problema. Neste caso, assume-se que as situações-problema correspondem a dificuldades e obstáculos abertos que admitem mais de uma solução específica, e que abordar os conflitos socioambientais significa declinar de forma expressa de dicotomias usuais no campo ambiental, apontando em direção às ações positivas.

Para aprofundar esse debate, propôs-se uma mesa-redonda (MR-10) durante o V Encontro da Associação Nacional de Pós-Graduação e Pesquisa em Ambiente e Sociedade - V ENANPPAS, em 2010, de forma que se pudesse explorar diversos ângulos de análise de conflitos socioambientais, educação ambiental e participação social na gestão ambiental. Cada um dos debatedores ${ }^{2}$ da mesa-redonda foram orientados a refletirem sobre as temáticas acima tendo como ponto de partida o artigo de Saito et al, 2008, que traz as bases teórico-metodológicas da produção do material didático Probio-EA ${ }^{3}$ em que o potencial educativo dos conflitos socioambientais é explorado. A partir do texto, cada convi- dado produziu sua própria reflexão sobre o conjunto das temáticas propostas para a mesa-redonda ou em parte delas, de forma independente.

Muito embora a origem da concepção de mesa-redonda resida no material didático Probio-EA, e seu referencial teórico-metodológico, a proposta da mesa-redonda não se esgota no mesmo, visto que as questões objeto de debate são de natureza mais ampla. Justamente por isso, parte dos convidados não guarda familiaridade (relação com a produção ou utilização) com o material, de forma que possamos apresentar uma rica contribuição para o avanço do conhecimento teórico-metodológico no campo da Educação Ambiental.

A mesa-redonda teve uma dinâmica baseada numa primeira rodada de exposição de cada debatedor, seguida da sistematização de um conjunto de questões decorrentes das exposições, que representavam uma provocação renovada aos mesmos, que se expressaram numa segunda rodada de argumentações. Finalmente, tivemos uma terceira rodada, após questionamentos do público. O presente texto é um esforço de síntese, que exigiu a supressão de parte da riqueza argumentativa e dialógica dos debatedores entre si e para com o público, devido às limitações para formatação como artigo para publicação nesta revista.

As diversas óticas para o debate: primeira rodada da mesa-redonda

Foi solicitada uma primeira intervenção de cada debatedor, em que discorressem sobre os quatro focos ou temas propostos como conteúdo da mesa-redonda: Conflitos socioambientais e os mitos da participação social; Conflitos socioambientais e as incertezas das condições para a educação ambiental em meio aos problemas e conflitos; Resolução de Conflitos socioambien- 
tais - ações mediadas pela razão instrumental e interesse emancipatório; Ações positivas como práticas dialógico-problematizadoras na realidade concreta.

\section{Exposição 1.1: Luciano Fernandes Silva e Luiz Marcelo de Carvalho}

Um dos caminhos potencialmente relevantes quando lidamos com a temática ambiental em processos educativos está diretamente relacionado com a possibilidade de exploração de controvérsias e conflitos socioambientais em práticas de educação ambiental. É a partir da compreensão de que as controvérsias e os conflitos socioambientais apresentam um grande potencial para explicitarmos a complexidade inerente à temática ambiental, descontruindo, assim, as dicotomias usuais no campo ambiental, que nos parece legítimo considerá-las como um dos possíveis princípios metodológicos para as nossas práticas de educação ambiental.

Por princípios metodológicos entendemos as ideias-chave que organizam e orientam metodologicamente o trabalho do educador. Assim posto, podemos dizer que considerar as controvérsias e os conflitos socioambientais como princípios metodológicos para práticas de educação ambiental significa necessariamente considerá-las como orientadoras na definição de objetivos, na seleção de conteúdos, de sequências didáticas e procedimentos metodológicos e de formas de avaliação.

As controvérsias e os conflitos socioambientais possibilitam a emergência de outros saberes em nossas práticas e abrem caminhos para a inclusão das subjetividades em nossos sistemas explicativos. Elas possibilitam afastarmo-nos dos conceitos de harmonia, verdade absoluta, totalidade, determinismo, universo mecânico e neutralidade, normalmente presentes nos discursos que versam sobre a temática ambiental. Entendemos que elas induzem ao pensamento crítico ao retomar os questionamentos direcionados para a visão de mundo moderna e suscitam o diálogo entre diferentes formas de saber.

As controvérsias socioambientais, por exemplo, podem ser desencadeadas por diferentes razões, mas elas essencialmente envolvem pontos de vista diferenciados em relação a determinado tema. Desse modo, falamos em controvérsias quando um determinado tema suscita, nos diferentes atores sociais envolvidos, posicionamentos políticos, sensibilidades éticas e estéticas diversificadas, ou diferentes maneiras de interpretar uma dada realidade.

Já os conflitos socioambientais estão relacionados com situações-problema que evidenciam conflitos presentes na esfera social que promovem impactos ambientais sobre a biodiversidade (SAITO et al., 2008). Alonso e Costa (2002, p.12), por sua vez, assumem que "a definição do termo é em si mesma um problema, com usos polissêmicos na literatura". Assumimos aqui a proposta de Scotto (1997) em que conflitos sociambientais são reconhecidos como aqueles

(...) conflitos que têm elementos da natureza como objeto e que expressam relações de tensão entre interesses coletivos e interesses privados. Em geral, eles se dão pelo uso ou apropriação de espaços e recursos coletivos por agentes econômicos particulares, pondo em jogo interesses que disputam o controle dos recursos naturais e o uso do meio ambiente comum... (SCOTTO, 1997, p. 4)

Para as perspectivas educacionais que se voltam para o reconhecimento, a avaliação e o enfrentamento de problemas de âmbito local ou regional os conflitos socioambientais podem ser tomados como um caminho bastante produtivo no sentido de trazer para a discussão vozes di- 
versas sobre questões mais próximas dos educandos (SAITO et al., 2008; MANZOCHI, 2008). Estas possibilidades levam vários autores a reconhecer um grande potencial nas controvérsias e/ou conflitos socioambientais como caminho privilegiado para a concretização das propostas de contextualização das práticas educativas, sobretudo aquelas diretamente relacionadas com a temática ambiental.

No que diz respeito às atividades educativas que envolvem especialmente aspectos da temática ambiental, temos verificado a necessidade de superar as estratégias educacionais ainda muito restritas às perspectivas preservacionistas/ conservacionistas ou biologicistas, que apontam, na maioria das vezes, para perspectivas comportamentalistas e pragmáticas na solução dos problemas ambientais e, por isso, descontextualizadas ou contextualizadas de forma ingênua ou simplista.

\section{Exposição 1.2: Jacy Bandeira Almeida Nunes}

Analisando a Política Nacional de Educação Ambiental no país, observamos que a Educação Ambiental proposta comporta uma dimensão ética, política, pedagógica e epistemológica, que se articulam na busca pela superação dos problemas socioambientais. Tal perspectiva dá a educação ambiental o sentido de processo educativo que deve propiciar a construção de valores, conceitos, habilidade e atitudes, que torne o sujeito capaz de realizar a leitura crítica da realidade onde atua, utilizando os conhecimentos científicos para transformá-la. Paradoxalmente, observa-se que as práticas, vinculadas à educação ambiental, apontam a adoção de "arranjos paliativos”. Os alunos não são mobilizados para uma postura crítica de busca por alternativas para superação e desvelamento dos problemas que lhes são próximos, consequentemente, é preocupante a ausência de participação efetiva nos processos decisórios no tange as ações que interferem na qualidade do ambiente em que vivem.

Várias são as fragilidades que caracterizam a Educação Ambiental no Brasil: a) A estruturação das aulas na forma de disciplinas que fragmentam o conhecimento e dificulta o estabelecimento dos nexos entre os diferentes saberes necessários a compreensão do meio ambiente; b) Ênfase nas questões teóricas/abstratas com conteúdos descontextualizados e pontuais; c) A adoção de uma visão cartesiana, onde a escola é uma mera transmissora de conhecimento e o ato de ensino uma ação individual e centrada no professor; d) Carência de recursos financeiros, didáticos e humanos, bem como na infraestrutura disponível para realização das atividades, principalmente de atividades práticas; e) A Educação Ambiental com uma dimensão ‘optativa' no currículo, ou seja, um conteúdo a ser incluído, numa carga horária ‘já sobrecarregada de conteúdos'; e f) Predomínio da razão instrumental. Tal quadro é totalmente divergente do que estabelece a legislação nacional, enquanto condição para realização da Educação Ambiental, mas que aparece na maioria das escolas brasileiras e a descaracteriza. Frente a tal horizonte a questão emergente representa um desafio aos educadores ambientais: Como contribuir efetivamente para a conscientização em face das questões socioambientais?

$\mathrm{Na}$ ótica Freireana, conscientização implica no "engajamento", isto é, numa forma de compromisso histórico com a transformação da realidade, na mobilização de saberes, competências e habilidades em prol da emancipação do sujeito e do grupo, frente a sua "condição de opressão", assim como numa metodologia dialógica e problematizadora. Se educar implica em dialogar 
com o outro e com o ecossistema, então co-implica o reconhecimento do outro como sujeito, portador de um saber a ser respeitado. O sentido vital da educação ambiental propicia a "formação da consciência ambiental" reconhecendoa como um processo dinâmico e dialógico através da práxis. O desvelamento crítico e dialógico da realidade implica na atuação sobre os conflitos socioambientais que caracterizam a dinâmica da sociedade contemporânea, na busca por novas perspectivas de análise e soluções para as questões socioambientais.

Para Freire, ser um sujeito consciente vai além do 'conhecer' a realidade através da transmissão/apreensão passiva de informações. Trata-se de buscar o conhecimento para uma atividade crítica, reflexiva e fundamentada por um projeto social emancipatório e ambientalista. O sujeito capacita-se para realizar a interpretação dos conflitos, utilizando os fundamentos científicos bem como o reconhecimento da existência de uma pluralidade de formas de conhecimento (SANTOS, 2007) para a participação ativa na transformação da sociedade. A dinâmica de formação da consciência ambiental passa pela conquista nos movimentos sociais, pela luta ecológica e pelos ideais da educação ambiental.

Portanto, pensar na possibilidade de utilizar os conflitos socioambientais como elementos indutores do processo de ensino-aprendizagem, representa a possibilidade de desvelar de forma critica, dialógica e contextualizada a realidade, frequentemente vinculada a intencionalidades nem sempre explícitas e atreladas a um modelo de sociedade não-compatível com a emancipação do sujeito. Por fim, é vital pôr em prática uma Educação Ambiental que promova a participação e a cidadania ativa - através da mobilização consciente, reflexiva e fundamentada teoricamente nos conhecimentos científicos e nas experiências exitosas (soluções viáveis-possíveis).

\section{Exposição 1.3: Aloísio Ruscheinsky}

A ênfase no mito da participação social permite adentrar também no mito da resolução dos conflitos socioambientais pela via da gestão integrada pelas forças sociais locais. A participação na gestão dos conflitos socioambientais remonta à consideração deste fenômeno como questão componente da esfera pública, portanto relaciona-se com mudanças dos atores sociais e do Estado na sua forma de operar, incluindo a gestão participativa (LOPES, 2006, p. 49). A participação pode ser desejável no que diz respeito à resolução dos conflitos, mas ao mesmo tempo parece relevante averiguar a existência de interesses contraditórios, ou de tal forma opostos, que a participação possa ser irrelevante como possibilidade de resolução desses conflitos. Isto conformaria então o mito da possibilidade das resoluções desses conflitos socioambientais a partir da participação ${ }^{4}$.

A questão das incertezas em relação às soluções ajeitadas na educação ambiental: a possibilidade da gestão de fato integrada, especialmente na medida em que existe uma distinção no que diz respeito ao discurso e as práticas dos atores socioambientais convocados para esse modelo de gestão partilhada, mas situados em posições sociais distanciadas. Os discursos em conflito decorrem dessas posições sociais distintas, em cujo contexto ao mesmo tempo se anseia uma gestão que possa ser democrática. Para este intento se questiona a cultura política vigente em amplos setores da sociedade brasileira - embora alguns setores possam se dizer referenciados ao horizonte democrático -, que deixa muito a desejar no que diz respeito a uma cultura efetivamente de- 
mocrática das informações ambientais ${ }^{5}$. Esta última considera relevantes os patamares de negociação das demandas, bem como o outro como interlocutor e não como um opositor a superar, para que uma única posição seja estabelecida.

Diria que a educação ambiental ganhará muito na sua própria lógica especialmente a nível local quanto mais conseguir de fato debater as lógicas de poder e as lógicas da própria desigualdade nos diferentes campos, compreendendo assim a redistribuição de recursos materiais, sociais, políticos, culturais e simbólicos (SANTOS, 2007). Quanto mais se atrela a educação ambiental somente à dimensão ambiental, esta perderá abrangência e também a possibilidade de se qualificar como uma alternativa efetiva às relações desiguais de poder. Do ponto de vista da dialética não há certeza de eficiência nos projetos de educação ambiental, pois não existem caminhos previamente dados ou um processo que possa garantir que por tal principio, em tais circunstâncias, teremos eficácia nas atividades. De outro, convém prezar pelos princípios e pelas metodologias, mas não como algo predeterminado, e a dialética permite neste caso o discernimento adequado e compreender as causas.

Os conflitos socioambientais e a questão das ações mediadas, tendo de um lado a razão instrumental, e, de outro, a agenda dos interesses emancipatórios, entre um indivíduo hedonista e um sujeito com potencial emancipatório e reflexivo que associa o cotidiano e as escolhas de consumo com uma cadeia de reações (COSTA, 2004, p. 77): esse confronto, de fato, é permanente nas contradições da sociedade contemporânea. Enquanto cientistas, ambientalistas, cidadãos, estamos permeados por essa contradição, de um lado a razão instrumental, do outro lado o desejo, a aspiração, as práticas emancipatórias. Essa dialética de alguma forma povoa o nosso horizonte na medida em que, por mais que aspiramos a ser libertários e contestadores, também nos reportamos à dimensão normativa.

No curso da história o desafio da contestação, com alguma eficácia, incide na insistência em uma perspectiva libertária, aliada à regulamentação dessas demandas, pois do contrário a iniciativa fica como que alheia ao sistema em que se engendra a gestão dessas demandas $^{6}$. Por um lado, como ambientalistas estamos permeados pela matiz analítica, especialmente guiados a partir de conhecimentos científicos com análise objetiva, mas ao mesmo tempo, também temos uma perspectiva prescritiva, para não sonegar as contribuições e o conhecimento para uma prescrição de comportamentos, de resolução de conflitos, dentre outros aspectos (JANTSCH, 2009). Há também a lógica dialética entre o emancipatório e o modernizador: de fato um processo modernizador está em curso e não podemos ignorá-lo ou estancálo. Ao mesmo tempo, a questão emancipatória instiga como alternativa ao processo modernizador, seja a partir da tecnologia, do sistema de produção, da própria cultura.

O debate referente à resolução de conflitos socioambientais, nas contingências das ações mediadas pela razão instrumental ou pela solidariedade emancipatória revela que existem formulações teóricas e perspectivas metodológicas que de alguma forma querem redefinir a correspondência desejável entre a civilização socioambiental emergente e as práticas adequadas.

\section{Exposição 1.4: Fabio da Purificação de Bastos}

Conflitos socioambientais, para os autores do material didático do Probio-EA, correspon- 
dem a situações-problema que evidenciem os conflitos na esfera social e promovem impactos ambientais sobre a biodiversidade. Embora na minha opinião este conceito educativo-ambiental seja uma criação com bom potencial dialógico-problematizador, no âmbito da equipe multidisciplinar produtora teve pouca compreensão teórico-prática.

Talvez isso se deva à nossa formação acadêmica que dicotomiza o tripé ciência-tecnologia-sociedade, denominada por alguns autores de cientificista. Do ponto de vista dialógico-problematizador, isso implica em priorizar problemas acadêmicos, mesmo que vinculados epistemologicamente às ciências ambientais, em detrimento de situaçõesproblema oriundas da realidade concreta.

A transposição didática de primeira ordem realizada a partir da produção científica da referida área gerou, de forma indissociável e acoplada, pares de portifólios conflitos-ações. Explicitam origem e natureza dos conflitos, cujas soluções, orientadas e apoiadas nos conhecimentos científico-tecnológico e tradicional, descrevem ação positiva, como solução negociada na esfera da conscientização, na perspectiva da justiça social e sustentabilidade socioambiental.

Embora na ocasião da produção do referido material não tenhamos problematizado a temática "conflitos socioambientais e os mitos da participação social", o par conflitos-participação esteve presente como fio epistemológico. $\mathrm{Ou}$ seja, a participação popular contemplada na produção didática, em especial no componente ação positiva, jamais foi opacizada ou tratada como um mito. Ao contrário disso, nossa compreensão educacional do conceito de conscientização (muito citado nos trabalhos de educação ambiental) esteve diretamente relacionado com o de ação, principalmente pela nossa adesão à teoria da atividade (por guardar bom interfaceamento com a teoria da ação dialógico-problematizadora).

No que diz respeito ao procedimento educacional vislumbrado, cuja mediação do material didático produzido é essencial, tem significativo peso o movimento codificação-descodificação, nos termos apresentados por Freire (1983). Na prática, isso exige problematização da realidade por meio de situações-problema, mapeando e explicitando os conceitos-chave e secundários necessários e operacionalizados nas soluções (isso se denominou curricularmente de simetria invertida, ou seja, primeiro aborda-se os problemas, para depois os conceitos, leis e fenômenos científicos).

Portanto, o recorte temático contraditório "conflitos socioambientais e as incertezas das condições para a educação ambiental em meio aos problemas e conflitos", embora no momento da produção didática não tenha sido problematizado, pode-se dizer que a prática educacional mediada pelos referidos materiais é obstaculizada, principalmente por isso. Dito de outra forma, professores (de ciências naturais majoritariamente) ao descodificarem ideologicamente a perspectiva educacional dos materiais didáticos, muitas vezes sequer se interessam em problematizá-lo ou dialogar sobre os conflitos e ações abordadas.

Para nós, isso não significa que compreendam os conflitos socioambientais (situações-problema), dicotomias usuais no campo ambiental e apontamentos sobre a direção das ações positivas (soluções viáveis-possível). Ao invés disso, significa que não compartilham com a conduta político-pedagógica do processo de conscientização dialógico-problematizador.

Nossos resultados de pesquisa educacional obtidos em processos de investigação-ação, implementados com professores e estudantes do 
ensino fundamental da escolaridade brasileira, nos permitem afirmar que a resolução de conflitos socioambientais abordados nos portifólios é percebida como ação mediada pela razão instrumental e interesse emancipatório. Contudo, isso não tem bom potencial gerador na realidade socioeducativa, a não ser que seja orientada por nós e "exigida" como atividade de estudo nos cursos de formação continuada de professores.

A problematização que tem sustentado o diálogo no escopo de nossa equipe universitária é: se, por um lado, este trabalho educativo sofre resistência daqueles comprometidos ou aderidos com aqueles que impactam o ambiente de forma irracional e inconsequente, por outro, também se coloca frontalmente contra o trabalho majoritário de educação ambiental realizado nas escolas.

Talvez a questão essencial no escopo da educação como prática da liberdade seja a tematizada por "ações positivas como práticas dialógico-problematizadoras na realidade concreta". Se no processo de descodificação mediado pelo material produzido, as ações abordadas nos portifólios não foram compreendidas como práticas dialógico-problematizadoras na realidade concreta do ambiente, a intencionalidade educacional dos autores efetivamente se esvaiu.

Embora saibamos que a leitura nunca pertence ao autor, mas sempre ao leitor, no escopo educacional a dialogicidade entre educador e educando guia o processo e explicita a intencionalidade da autoria. Em outras palavras, até mesmo nas exposições realizadas dos portifólios conflitos-ações, os resultados dos surveys realizados sinalizam que a intencionalidade dialógicoproblematizadora é percebida e compreendida. Contudo, repitamos, os materiais didáticos nesta perspectiva educacional e de conscientização dialógico-problematizadora tem demonstrado baixo potencial gerador.

O debate gerando novas questões de diálogo: Segunda rodada da mesa-redonda (por Carlos Hiroo Saito)

Com base no exposto, algumas questões surgem para aprofundamento do debate na mesaredonda, à luz de suas experiências e pesquisas. As questões emergentes dos discursos dos debatedores, direta ou indiretamente apreendidos, são as seguintes, que foram apresentadas para nova análise pelos debatedores:

Do tema Conflitos socioambientais e os mitos da participação social: Há um culto ao mito de que a descentralização atua irremediavelmente como indutor de maior democratização e eficiência na gestão das políticas públicas? De onde falamos quando levantamos a possibilidade da ação popular ser um mito na seara da participação? Quais os parâmetros desta participação popular, contextualizada pela opressão cultural geradora de impactos ambientais, muitos deles produzidos por ações fora da esfera da conscientização? Ação participante no âmbito socioambiental, guiada por organizações populares e universitárias, tem possibilidade de produzir ou de influir sobre mito apontado?

Do tema Conflitos socioambientais e as incertezas das condições para a educação ambiental em meio aos problemas e conflitos: Como articular temas sociais e situações problemas tal que permitam discussões envolvendo aspectos dos conflitos socioambientais? O processo social conduz a um imaginário de dominação ou uso instrumental e com uma profunda dissociação entre os seres humanos e o nexo com os recursos naturais? Qual a medida da incerteza de nossas ações, dada nossa condição humana, quando nossa intencionalidade é preservar a biodiversidade? Será que ao optarmos pela educação como 
prática da liberdade, as incertezas nas condições de contorno de nossas ações têm alguma possibilidade de serem desprezadas científico-tecnologicamente?

Do tema Conflitos socioambientais: ações mediadas pela razão instrumental e interesse emancipatório: Como a Educação Ambiental pode contribuir efetivamente para o exercício da cidadania diante das questões socioambientais? A ocorrência dos conflitos socioambientais remete a circunstâncias da desigualdade no acesso aos recursos naturais e a desproporcionalidade na distribuição dos riscos decorrentes dos processos de transmutação da natureza em bens de uso? Como fazer com que a dinâmica conflitiva possa fazer emergir atribuição de significados distintos ou pretensões excludentes de apropriação, tal que denunciem a falácia do ideário consensualista e universalista? Como fortalecer ações positivas orientadas pela perspectiva emancipatórias, em contextos opressivos e impactantes no ambiente? Em situações que predominam a conhecimento popular e/ou tradicional, como dialogar sobre situações-problema pautados pelo conhecimento científico-tecnológico?

Do tema Ações positivas como práticas dialógico-problematizadoras na realidade concreta: Ações positivas, no escopo afirmativo, perdem seu caráter dialógico-problematizador, quando o braço do Estado atua sob a tutela do judiciário? A construção de uma sociedade ambientalmente sustentável, alicerçada nos princípios da equidade, solidariedade, democracia, justiça social, responsabilidade, apregoa uma utopia ao enfatizar as perspectivas crítica e emancipatória da Política Nacional de Educação Ambiental? Será que a hegemonia interpretativa pode nos auxiliar na estratégia dialógico-problematizadora, estruturante das ações positivas?

\section{Exposição 2.1: Luciano Fernandes Silva e Luiz Marcelo de Carvalho}

A partir das perspectivas apresentadas, consideramos relevante investigar se os relatos de pesquisa em Educação Ambiental reconhecem os conflitos socioambientais como um princípio metodológico para a contextualização da temática ambiental em atividades de educação ambiental.

Num estudo exploratório, buscamos por artigos que indicassem articulações entre processos de educação ambiental e conflitos socioambientais. Nosso interesse esteve voltado para os trabalhos apresentados nas atas dos seguintes eventos: Encontro da Associação Nacional de Pós-Graduação e Pesquisa em Ambiente e Sociedade (ENANPPAS, Grupo Temático Ambiente, Sociedade e Educação), Reunião Anual da Associação Nacional de PósGraduação e Pesquisa em Educação (ANPEd, GT22 - Educação Ambiental) e Encontro de Pesquisa em Educação Ambiental (EPEA) dos últimos 09 anos, com exceção do EPEA de 2009.

Em um primeiro momento pudemos identificar 11 trabalhos no qual estava presente o termo conflito socioambiental. A partir de leituras cuidadosas deles descartamos 4 desses 11 trabalhos inicialmente selecionados. Observamos nesses que o termo "conflito" aparece dissociado de teorias e/ou reflexões mais elaboradas sobre o campo dos conflitos sociais e/ou socioambientais. Nesses 4 trabalhos é possível substituir a referência a "conflito ambiental" por "problema ambiental", sem que isso altere significativamente o texto em questão. Além disso, dos 7 trabalhos restantes descartamos mais 2 , tendo em vista que os dados apresentados nesses textos não atendiam aos critérios estabelecidos para a seleção dos 
relatos. Por fim, nosso grupo de relatos de pesquisa ficou constituído por 5 trabalhos.

Verificamos que nesse grupo há 3 relatos que indicam de forma explícita algumas potencialidades educativas no campo do direito ambiental.

O trabalho de Malagodi (2008) indica que temas da Justiça Ambiental articulados com processos educativos são potencialmente favoráveis para explicitar questões sobre política, democracia e os atuais padrões de insustentabilidade característicos de nossa sociedade. Para o autor, é incoerente refletir sobre aspectos da problemática ambiental em processos educativos descontextualizados.

Já o trabalho de Peres e Santana (2007), se constitui em um ensaio teórico que tem como um de seus objetivos avaliar diferentes possibilidades de incluir o Direito Ambiental em processos educativos, sobretudo como instrumento para a solução dos conflitos socioambientais. Os autores consideram fundamental a necessidade de serem implementadas estratégias educacionais diferenciadas para a formação de cidadãos ativos. Nesse sentido, entendem que o educador deve considerar a possibilidade de identificar conflitos gerados pelo uso dos recursos naturais, como uma das possibilidades de ir em sentido oposto de práticas educativas descontextualizadas, ingênuas e simplistas que permanecem restritas às perspectivas biológicas e comportamentais da problemática ambiental.

O grande potencial educativo existente em um processo judicial que aborda conflitos socioambientais também é muito enfatizado no trabalho de Farias e Carvalho (2003). Chama a nossa atenção um aspecto nesse trabalho que não foi encontrado em nenhum outro, qual seja, o fato de que os autores utilizam o referencial teórico que na literatura é conhecido como enfoque $\mathrm{Ci}$ ência, Tecnologia, Sociedade e Ambiente -
CTSA. Para esses autores, a utilização de aspectos de conflitos socioambientais do campo do Direito Ambiental em processos educativos possibilita ao educador se aproximar de uma compreensão mais dinâmica e complexa dos problemas ambientais, sobretudo ao lidar com direitos coletivos e difusos, modos e recursos de defesa ambiental, processos de participação política e debate de valores.

Os outros dois trabalhos analisados destacam outras potencialidades educativas dos conflitos socioambientais: Manzochi e Carvalho (2008, p. 8), apontam que entre os potenciais educativos da análise dos conflitos socioambientais está

(...) a percepção de que, ao sair dos discursos genérico na EA, por meio do trabalho com situações contextualizadas (o caso de conflito socioambiental real), abre-se a possibilidade de se chegar à Ação política, no trabalho educativo.

Já o trabalho de Silva (2007, p.11), aponta para a necessidade de serem explorados conflitos socioambientais em filmes educativos, sobretudo por considerar que

(...) um filme pode mostrar alguns temas geradores no sentido de apresentar os conflitos pelo acesso e pelo uso dos recursos naturais, interesses privados e públicos relacionados à problemática ambiental, a responsabilidade diferenciada dos diversos atores sociais na degradação ambiental, as maneiras como os impactos ambientais atingem diferentes camadas sociais.

Os relatos de pesquisa analisados apontam de forma explicita algumas potencialidades educativas dos conflitos socioambientais. Destacamos as sugestões que podem nos levar a problematizar o contexto no qual estudamos os problemas ambientais.

A ideia básica é a de que os conflitos socioambientais estão relacionados com situações lo- 
cais. Esses conflitos apresentam importantes perspectivas para o reconhecimento, a avaliação e as propostas de enfrentamento de problemas de âmbito local ou regional, possibilitando-nos, enquanto educadores, problematizar diferentes aspectos do nosso cotidiano.

Também chama a atenção o fato dos autores terem destacado que os conflitos socioambientais nos possibilitam articular, no processo educativo, outras dimensões da realidade que não ficam restritas apenas ao conhecimento. Nesse sentido, os autores indicam a possibilidade de trabalharmos questões de natureza política e valorativas.

Por fim, esses trabalhos parecem indicar que a temática ambiental vista a partir dos conflitos socioambientais retoma algumas das críticas voltadas para a visão do mundo moderno, sobretudo ao sugerir que na análise dos conflitos outros saberes, além dos advindos do processo de produção científica, devem ser reconhecidos.

\section{Exposição 2.2: Jacy Bandeira Almeida Nunes}

Os educadores, de uma forma geral, acabam fazendo arranjos paliativos em relação às questões ambientais, fazendo com que os sujeitos desacreditem do seu potencial - o que descaracteriza aquilo que está posto enquanto Educação Ambiental. Plantar uma árvore na semana do meio ambiente, fazer limpeza nos rios, sem uma discussão profunda das causas e da realidade do sujeito, são atividades pontuais, insuficientes para viabilizar a formação para uma leitura critica dessa realidade. Porém, ao conhecer a proposta da produção do material didático Probio-EA, novas perspectivas foram vislumbradas para os trabalhos do Núcleo Universitário de Estudo Socioambiental, da UNEB-Campus Jacobina a partir da utilização dos conflitos socioam- bientais, porque discutiam exatamente aqueles problemas que inquietavam a comunidade, e que, ao mesmo tempo, incomodavam vários atores sociais. A solução vinha da própria comunidade, e as pessoas então percebiam que havia uma forma de se posicionar enquanto sujeitos, e havia também outra realidade por trás daquela aparente. A aderência aos problemas muitas vezes impede a autonomia sociopolítica para buscar alternativas à situação ou não se percebam como sujeitos atuando sobre o processo socioambiental. Por isso, o trabalho a partir dos conflitos socioambientais tem potencial para a formação de um sujeito com uma leitura crítica para desvelar os interesses vigentes. Passamos a desenvolver, assim, processos que tem como teoria-guia a metodologia dialógica Freiriana: pela problematização das questões da própria realidade, pudemos tomar os conflitos socioambientais como elementos indutores para uma prática educativa que possibilitasse ao sujeito a leitura crítica da realidade.

Sobre a possibilidade de êxito da educação ambiental como formação de uma consciência socioambiental: Numa pesquisa realizada para verificar quais os sentidos e significados que os docentes de ensino médio atribuíam à questão de educação ambiental, constatamos que ratificam um discurso instituído, mostrando inclusive uma preocupação em desenvolver a interdisciplinaridade proposta nas diretrizes. O que está posto na fala não é o que acontece na prática. Detectamos que as atividades voltadas para a questão socioambiental aconteciam de forma desarticulada dos outros conteúdos, por meio da imposição de projetos pelas secretarias municipais e estaduais de educação. Portanto, apesar do discurso desses sujeitos, o que verificamos é a ausência real de uma prática efetiva que contemple as diversas dimensões da educação ambiental. Nas representações docentes a educação 
ambiental é importante, mas não consegue trazer resultados locais efetivos. $\mathrm{O}$ foco dos trabalhos, frequentemente, volta-se para amplos problemas ambientais entre eles o efeito estufa, as mudanças climáticas, a destruição da mata atlântica. Os alunos, no território do Piemonte da Chapada Diamantina, que no transcorrer da aula recebem informações sobre os grandes problemas ambientais, ao sair desta, junto com os pais, vão tocar fogo nas matas da serra, porque existe o mito de que colocar fogo vai trazer chuva para o local. Assim sendo, os saberes tradicionais desses sujeitos não são levados em consideração. São detentores de saberes e de práticas sociais que precisam ser ressignificadas a partir da instrumentalização da ciência a fim de compreender as implicações oriundas das ações empreendidas.

A questão do desenvolvimento da consciência socioambiental na escola deve começar nos cursos de formação profissional, de maneira que os professores não se atenham apenas aos fundamentos daquilo que acreditam ser educação ambiental. No discurso, os docentes acreditam realmente que estão fazendo um trabalho muito importante; este é o ponto inicial para um diálogo com esses sujeitos: é preciso estabelecer a reflexão crítica às ações docentes e dar essa contribuição aos processos educativos.

Portanto, o trabalho de formação deve tocar justamente nos conflitos da realidade, muitas vezes não percebidos, e é a sua explicitação que de alguma forma vai auxiliar na emergência de sujeitos engajados. A conscientização passa, antes de tudo, pela possibilidade da autonomia sociopolítica desse sujeito ou seu engajamento num movimento, lutando efetivamente pelo que acredita. Se o cidadão acredita que a educação ambiental pode trazer retorno efetivo, vai estar colaborando na construção de valores voltados para a sustentabilidade do planeta.

\section{Exposição 2.3: Aloísio Ruscheinsky}

Em relação à discussão em curso parece relevante interrogar como, onde e quando ocorrem os processos sociais referidos como participação em instâncias deliberativas e decisórias. De fato, instâncias forjadas para serem de participação em deliberações e democráticas na decisão, por vezes, mesmo dentro das regras do jogo, fazem os processos soarem menos democráticos, de gestão pouco integrada e não-descentralizados como parecem ser, ou como seus partícipes em seu discurso propõem.

Mesmo a percepção dos problemas ambientais ou da gestão integrada, apesar de sumamente importante, por vezes também não é suficiente para produzir alternativas. O processo de participação e de diálogo gerado em consonância com os outros é infindável e todos podemos cometer equívocos na percepção e na compreensão do que seja um processo de participação de fato descentralizado, pois igualmente não há um término que diz respeito à descentralização ou democratização dos processos. Ou como dirá Santos (2007, p. 94) a "natureza da ecologia de saberes constitui-se mediante perguntas constantes e respostas incompletas". Os espaços sociais são de tal forma dinâmicos que sempre há algo por fazer, assim como vige uma utopia a propósito dos processos de democratização.

Ainda há a questão do processo da indução de uma cultura material e imaterial, que anima e subsidia o mito do consumo sob o pretexto de que somente o consumo produz bem-estar social, ou seja, quanto maior o consumo, maior o bem-estar social. Este mito que nos permeia está largamente difundido, como o mito do progresso (DUPAS, 2006): mais salário, emprego, exportação como possibilidade de adquirir bens como lógica de ser feliz. Essa lógica vai com 
endereçamento quase que oposto ou no mínimo em conflito com a perspectiva de um processo de educação ambiental que busca introduzir uma lógica de uso mais racional, e, portanto, eqüitativo em relação aos bens naturais.

O conjunto da população brasileira pode não ter a realização efetiva ou a materialização da cultura de consumo, mas o anseio do acesso ao consumo constitui uma questão que permeia amplamente o imaginário. Enquanto ambientalistas somos bombardeados permanentemente por uma publicidade que prioriza outras dimensões que não aquelas que estamos considerando como uma gestão integrada, descentralizada e democrática em relação aos recursos naturais.

Os sujeitos nem sempre reconhecem os seus interesses claramente identificados e delimitados, bem como os conflitos socioambientais podem ser circunscritos do ponto de vista local e ao mesmo tempo ter ingerência global. A manifestação de interesses em face da legislação ambiental pode ser muito distinta, pois os indivíduos geradores dos conflitos ambientais e de processos de degradação poderiam vir a compreender que os seus interesses serão qualificados no médio prazo com um processo de preservação e de uma prática ambiental alternativa.

As práticas de educação ambiental possuem a qualificação de questionar a intensidade com que se manifesta o imaginário e os interesses econômico, cultural, político, simbólico, ou um novo código de conduta (LOPES, 2006). O questionamento dessa pluralidade é fundamental em qualquer processo crítico de educação ambiental.

Outra temática complementar é a perspectiva da utopia: como uma porta a partir de um horizonte que detém alguns elementos do contexto, mas ao mesmo tempo reforça, aprofunda e alarga alguns elementos importantes que não estão no contexto, porém possuem condições de possibilidades, de "vir-a-ser", em decorrência dos desdobramentos do jogo das forças sociais. A utopia como potencialidade de resolução dos conflitos socioambientais, dentro das condições e possibilidades da confluência de atores numa certa direção: a vontade política de atores que enunciam a mesma utopia em consonância com as condições de possibilidade (RUSCHEINSKY, 2010). A outra grande questão que está alinhada com a utopia relaciona-se com uma reflexão sobre a demanda da justiça ambiental conectada a um conjunto de direitos que vem se efetivado ao longo da trajetória de mais um século com a intensa conexão com o uso intensivo dos bens ambientais. A capacidade de inovação na gestão ambiental pode adicionar a dimensão verde aos direitos humanos, inclusive, questionando a ótica de direitos humanos ao agregar-lhes a dimensão da biodiversidade.

O debate apresentando representa uma reflexão profundamente imbuída de uma dialética, um encaminhamento para que ações positivas alicerçadas em práticas dialógico-problematizadoras na realidade concreta possam vir a se apropriar de instrumental epistemológico. Neste processo, como ambientalistas, não ficamos no aguardo da resolução consensual das negociações dos conflitos ou das certezas vendidas pela lógica de mercado. Isto nos aproxima de outras questões: como se articulam os mecanismos para agregar atores sociais, bem como articular entre si a critica socioambiental, a resolução urgente dos problemas e o encantamento com perspectivas alternativas?

\section{Exposição 2.4: Fabio da Purificação de Bastos}

A discussão inicial posta na produção do material didático Probio-EA era de não reproduzir a lógica de: primeiro eu ensino os conceitos e 
depois proponho problemas, para os estudantes aprenderem ciência. Essa é a simetria atual. O que nós chamamos na educação científico-tecnológica de simetria invertida, requer iniciar com alguns problemas reais, que tanto nós da ciência e tecnologia temos nos debruçado, quanto a sociedade tem se preocupado. A partir daí problematizar se as nossas ferramentas (que são os nossos conceitos, leis e princípios), resolvem nossas situações-problema, e ainda mostrar como os profissionais que estão atuando na área estão resolvendo isso de forma satisfatória ou não.

O fizemos tinha como referência téoricoprática, na esfera da didática chamada de conhecimento científico, as publicações produzidas pelo próprio Probio ${ }^{7}$, além de diversas publicações científicas de pesquisadores envolvidos nesses subprojetos e correlatos. Portanto, o que fizemos, chamamos de transposição didática de primeira ordem. Ou seja, esta era nossa referência: estudando esses materiais - que não são de natureza didática - produzimos um material didático, que guardasse coerência epistemológica, ou seja, que não produzisse incoerência conceitual. Além disso, mantivemos a relação pareada conflitos socioambientais e ações positivas (dialogicamente tínhamos relacionar problema-solução). E esse era outro desafio, porque tínhamos muitas ações que não poderiam para nós ser ações positivas, pois estas requeriam que fossem organizadas pela comunidade local, e necessariamente guardar coerência dialógico-problematizadora. Ou seja, a comunidade em diálogo com alguns atores externos a mesma, produzindo aquela solução viável-possível. A dificuldade que tínhamos na equipe era entender que não poderíamos trabalhar na perspectiva literalmente consensual, só porque a ação era de uma prefeitura ou ONG, e por conseguinte deveria ser automaticamente considerada ótima. Não era essa perspectiva edu- cacional, pois tínhamos que dispor na equipe uma ação, sobre determinado problema, com duas lógicas no mínimo, disponíveis, não só no pensamento, mas no par pensamento-linguagem, daqueles que viviam determinados momentos. Ao produzir materiais didáticos com as soluções que existiam concretamente, percebemos que muitos de nós sequer as conheciam, e eram soluções tecnológicas!

É importante alertar, pois, que a perspectiva dialógico-problematizadora nos "custa caro", porque somos orientados pela via do consenso, quando não necessariamente produzimos consenso. E, quando a gente não produz consenso, parece que o diálogo não é uma boa estratégia produtiva. O que estávamos vivendo de fato é a síntese cultural, mesmo sem uma solução consensuada, e apresentar isto, não como algo pronto e acabado, mas propondo novas questões para o diálogo-problematizador. Com isso estamos dizendo que "o conhecimento não está dado, nunca está acabado, e sempre precisa evoluir". É esta formação como prática para a liberdade que queremos viver, porque literalmente quem está atuando nesta perspectiva, sabe por exemplo, que não se pode parar de aprender enquanto vive.

Quando produzimos o par de portifólios no material didático Probio-EA sabíamos que era um fragmento em termos de conhecimento ${ }^{8}$. Por isso nos preocupamos significativamente em fazer o portifólio da ação ser mais articulado, em termos de "unidade estruturada do saber". Pois quando as pessoas começam a fazer ações de educação ambiental na escola, elas se afastam muitas vezes daquilo que a gente chama de conteúdo escolar. É preciso perguntar qual a rede conceitual estabelecida para determinados temas ambientais. E quando surgiam argumentos de que os ambientalistas ativos não eram pautados por uma parametrização conceitual, se fazia necessário apon- 
tar para um problema novo a esse respeito: se a gente não marca essa discussão no campo das ações positivas, parece que essas ficam desprovidas de valor. Valor escolar! Em situações onde predomina o conhecimento popular, quase justificamos o desmatamento e produção de carvão para sobrevivência humana. Então, como dialogar sobre situaçõesproblema, nos pautando por esse outro aspecto da cultura elaborada, que no caso citado, esclarece que essa prática é destruidora do ambiente? A outra questão articulada a isto, é que o sujeito que vai para a escola, é o mesmo ainda pratica queimadas, abate de forma indiscriminada os animais silvestres, entre outras ações impactantes. Ou seja, é preciso lembrar da transmissão-recepção, subjaz na produção de cartilhas informativas, pouco eficaz na mudança de atitudes. Portanto, o que organizamos como conteúdos culturais precisa construir valor e orientar ações! Trata-se de problematizar nossa incoerência existencial no ambiente, cotidianamente vivida! Mudar valores na prática não é algo rápido de fazer. Mudar valores e práticas precisa ser problematizado na estrutura do conhecimento, objeto do diálogo-problematizador. O essencial é definir e distinguir as lógicas que dão sustentabilidade ao diálogo-problematizador, quintessência do ser mais humano.

Considerações finais (por Carlos Hiroo Saito)

Em síntese, seguem os principais pontos apresentados no conjunto da mesa-redonda, segundo os quatro focos ou temas propostos:

Tema: Conflitos socioambientais e os mitos da participação social

- $\quad$ É vital pôr em prática uma Educação Ambiental que promova a participação e a cidadania ativa - através da mobilização consciente, reflexiva e fundamentada teoricamente nos conhecimentos científicos e nas experiências exitosas (soluções viáveis-possíveis).
- $\quad$ Os gestores das políticas ambientais não se colocam a interrogação se a população local considera admissíveis os impactos futuros sobre a forma de ocupação do território, os impactos gerados pela degradação ou escassez dos recursos naturais e os riscos socioambientais associados.

- As razões da elite política e econômica regional desconsideram as incertezas e os efeitos perversos amplamente denunciados pelo movimento ambientalista.

Tema: Conflitos socioambientais e as incertezas das condições para a educação ambiental em meio aos problemas e conflitos

- O cotidiano é freqüentemente insuficientemente problematizado na escola, sendo muito comum encontrar trabalhos educativos que simplesmente descrevem a existência de problemas ambientais próximos e secundários.

- Reconhecemos um grande potencial dialógico-problematizador nos conflitos socioambientais, como caminho privilegiado para a concretização das propostas de contextualização das práticas educativas como prática da liberdade, e para tanto, geram princípios metodológicos para práticas de educação ambiental.

- Há uma ambiguidade entre o discurso, a intencionalidade e a inequívoca inserção na lógica de circulação de mercadorias com seus respectivos impactos ambientais.

- Muitos professores, ao descodificarem ideologicamente a perspectiva educacional presente nos materiais didáticos, muitas vezes sequer problematizam ou dialogam sobre os conflitos e ações abordadas.

Tema: Conflitos socioambientais: ações mediadas pela razão instrumental e interesse emancipatório

- O desvelamento crítico e dialógico da realidade implica na atuação sobre os conflitos socioambientais que caracterizam a dinâmica da 
sociedade contemporânea, na busca por novas perspectivas de análise e soluções para as questões socioambientais.

- $\quad$ O processo de indução de uma cultura material e imaterial subsidia o mito do consumo como bem-estar social e como meta prioritária do processo civilizatório

- Os alunos afeitos às informações do senso comum precisam ser mobilizados para uma postura crítica de busca por alternativas para superação e desvelamento dos problemas que lhes são próximos

A resolução de conflitos socioambientais abordados nos portifólios são percebidos como ações mediadas pela razão instrumental e interesse emancipatório. Contudo, isso não tem bom potencial gerador na realidade socioeducativa, a não ser que orientada por nós e "exigida" como atividade de estudo nos cursos de formação continuada.

- $\quad$ Se, por um lado, este trabalho educativo sofre resistência daqueles comprometidos ou aderidos com aqueles que impactam o ambiente de forma irracional e inconsequente, por outro, também se opõe ao trabalho majoritário de educação ambiental realizado nas escolas.

Tema: Ações positivas como práticas dialógico-problematizadoras na realidade concreta - Pensar na possibilidade de utilizar os conflitos socioambientais, como elementos indutores do processo de ensino-aprendizagem, representa a possibilidade de desvelar a realidade concreta, de forma critica, dialógico-problematizadora e contextualizada, frequentemente vinculada a intencionalidades nem sempre explícitas, e ainda atreladas a um modelo de sociedade nãocompatível com a emancipação do sujeito.

- $\quad$ É vital pôr em prática uma Educação Ambiental que promova a participação e a cidadania ativa por meio da mobilização consciente, refle- xiva e fundamentada teoricamente nos conhecimentos científicos e nas experiências exitosas (soluções viáveis-possíveis).

- $\quad$ Se no processo de descodificação mediado pelo material produzido, as ações abordadas nos portifólios não foram compreendidas como práticas dialógico-problematizadoras na realidade concreta do ambiente, a intencionalidade educacional dos autores efetivamente se esvaiu.

- A mudança de valores e práticas é dependente da estrutura do conhecimento que é objeto do diálogo-problematizador.

- Não basta propor uma estratégia dialógicoproblematizadora, é essencial definir a lógica que se vai defender nesse diálogo-problematizador.

\section{Agradecimentos}

Agradecemos à Comissão Organizadora do V ENANPPAS pela oportunidade de realização da mesa-redonda MR-10, e à Luzia Etelvina de Almeida, pela transcrição da gravação da mesaredonda.

\section{Referências Bibliográficas}

ALONSO, A; COSTA, V. Por uma Sociologia dos conflitos socioambientais no Brasil. In: ALIMONDA, H. (Org.) Ecologia Política: Naturaleza, sociedad y utopia. CLACSO, 2002. COSTA, S. Quase crítica: insuficiências da sociologia da modernização reflexiva. Tempo Social, v.16, n.2. São Paulo, 2004. p. 73-100. DUPAS, G. O mito do progresso. São Paulo: Unesp, 2006. p. 309.

FARIAS, C.R.O.; CARVALHO, W.L.P. Desvelando Relações Ciência-Tecnologia-SociedadeAmbiente a partir de um Processo Judicial sobre Danos Ambientais. In: II Encontro de Pesquisa em Educação Ambiental. São Carlos-SP, 2003. 
Atas.., São Carlos-SP, II EPEA, 2003.

FREIRE, P. Pedagogia do Oprimido. Rio de Janeiro: Paz e Terra, 1983.

JANTSCH, A.P. Educação superior: mercadorização, formação, universidade pública e pesquisa crítico-emancipatória em tempo de realização plena do conceito de capital. In:.32 Reunião ANPEd, Caxambu-MG, 2009. Atas..., Caxambu, ANPEd, 2009.

LOPES J.S.L. Sobre processos de "ambientalização" dos conflitos e sobre dilemas da participação.

Horizontes

Antropológicos. v.12, n. 25. Porto Alegre, 2006. p. 31-64

MALAGODI, M.A.S. Justiça Ambiental: tema gerador para a crítica da modernidade da educação ambiental? In: IV ENANPPAS. 2008, Brasília. Anais... Brasília, 2008. Disponível em: <http:// www.anppas.org.br/encontro4/cd/ARQUIVOS/ GT9-514-222-20080510190736.pdf>. Acesso: jul. 2010.

MANZOCHI, L.H. Educação ambiental formadora de cidadania: as contribuições dos campos teórico-metodológicos de "conflito socioambiental" e "educação moral" para a formação continuada de professores. 2008.318 p. Tese (Doutorado em Educação Escolar) Faculdade de Ciência e Letras - Universidade Estadual Paulista, Araraquara-SP, 2008.

MANZOCHI, L.H.; CARVALHO, L.M. Educação Ambiental Formadora de Cidadania em Perspectiva Emancipatória: constituição de uma proposta para formação continuada de professores. In: 31 ${ }^{\text {a }}$ Reunião ANPEd, Caxambu-MG, 2008. Atas..., Caxambu, ANPEd, 2008.

PERES, R.S.; SANTANA, L.C. Educação Ambiental e Direito Ambiental: desvelando relações em práticas político-pedagógicas de ONGs ambientalistas. In: IV Encontro de Pesquisa em Educação Ambiental. Rio Claro-SP, 2007. Atas..,
Rio Claro-SP, IV EPEA, 2007.

RUSCHEINSKY, A. Sustentabilidades: concepções, práticas e utopia. In: GUERRA, Antonio (Org.). Sustentabilidades. Florianópolis: Ed. Univali, 2010. p. 63-86.

SAITO, C. H.; BASTOS, F. P.; ABEGG, I. Teorias-guia educacionais da produção dos materiais didáticos. Teorias-guia educacionais da produção dos materiais didáticos para a transversalidade curricular do meio ambiente do MMA. Revista Iberoamericana de Educación (Online), v. 45, p. 1-10. 2008. (Disponível em: http://www.rieoei.org/expe/1953Saito.pdf)

SANTOS, B.S. Para além do pensamento abissal: das linhas globais a uma ecologia de saberes. Novos Estudos - CEBRAP, n.79, São Paulo, 2007, p. 71-94.

SCOTTO, G (Coord.) Conflitos ambientais no Brasil: natureza para todos ou somente para alguns? Rio de Janeiro: IBASE, 1997.

SILVA, R.L.F.; O Meio Ambiente por Trás da Tela: concepções de educação ambiental dos filmes da TV escola. In: 30 ${ }^{\mathrm{a}}$ Reunião ANPEd, Caxambu-MG, 2007. Atas..., Caxambu, ANPEd, 2007.

\section{Notas}

${ }^{1}$ Este Debate é resultante dos trabalhos da mesaredonda "Conflitos Socioambientais, Educação Ambiental e Participação Social na Gestão Ambiental" do V Encontro da Associação Nacional de Programas de Pós-Graduação em Ambiente e Sociedade, ocorrido em outubro de 2010, em Florianópolis-SC.

${ }^{2}$ A mesa-redonda foi composta por um coordenador (Carlos Hiroo Saito) e quatro debatedores (Aloísio Ruscheinsky, Fabio da P. de Bastos, Jacy B. A. Nunes, e Luciano F. Silva, que substituiu de última hora Luiz M. de Carvalho). Considerando os dois últimos trabalharam articuladamente, para fins deste artigo, ambos apa- 
recem juntos como co-autores da mesma argumentação.

${ }^{3}$ Material didático de Educação Ambiental produzido em 2006 com o apoio financeiro do PROBIO/Ministério do Meio Ambiente/BIRDGlobal Environment Facility/CNPq (disponível em http://www.ecoa.unb.br/probioea/).

${ }^{4}$ As dinâmicas que se instauram ante a lógica dos conflitos e que se apresentam enquanto processos participativos, por vezes produzem efeitos contrários ao enunciado do seu próprio discurso: caso típico são audiências e consultas públicas. Caracterizam-se como instâncias que consagram o poder político vigente, a desigualdade da distribuição de poder e os atores predominantes na apresentação de suas plataformas, sem efetivamente gerar um processo comunicativo.

${ }^{5}$ Se de um lado, a gestão ambiental não se pauta por soluções consensualistas, por outro lado, a possibilidade de uma gestão integrada, ampliada e descentralizada dos conflitos socioambientais é também sempre um processo continuado, pois as resoluções parecem pouco definitivas. Nos aspectos dessa conflitualidade, pela sua dinâmica, os conflitos socioambientais ultrapassam àquilo que parecem ser, ousam-se mais abrangentes e complexos do que nós imaginamos.

${ }^{6}$ A sociedade civil está predominantemente orientada e legitimada pelas relações decorrentes do jogo das forças sociais internas, o Estado brasileiro, do federal ao local, parece ajustado às contradições desse jogo das forças sociais e políticas que operam de fora para dentro, em especial as grandes corporações e o capital especulativo.

${ }^{7}$ Projeto de Conservação e Utilização Sustentável da Diversidade Biológica Brasileira (Probio), coordenado pelo Ministério do Meio Ambiente, resultou do Acordo de Doação TF28309, entre o Governo brasileiro e o Fundo para o Meio Ambiente Mundial (Global Environment Facility-GEF)/Banco Internacional de Reconstrução e Desenvolvimento (BIRD) em 1996. O Probio apoiou a realização de pesquisas e o desenvolvimento de subprojetos demonstrativos e avaliações, em nível de biomas, para a conservação e a utilização sustentável da diversidade biológica.
${ }^{8} \mathrm{O}$ material didático tinha, na frente, fotos (ele não tinha gravuras, esquemas gráficos) e, no verso, descreve a situação estampada nas fotos, com uma linguagem mais próxima daquilo que chamamos, na universidade, de senso comum ou conhecimento popular. 